\title{
Aventuras num rápido avanço
}

Nadeau, K. G. (1996) Vida, amor e trabalho para o adulto ADD. New York: Brunner/Mazel.

Hiperatividade, durante anos, foi uma desordem reconhecida estritamente em crianças. A partir de 1980, essa desordem foi oficialmente reconhecida como Desordem por Déficit de Atenção (DDA) com dois subtipos: com e sem Hiperatividade. No mesmo ano surgiu uma nova categoria: a do tipo Residual, que foi adicionada porque algumas crianças e adolescentes continuaram a apresentar problemas de atenção quando se tomaram adultos.

Em 1990, Dr. Alan Zametkin, do Instituto Nacional de Saúde Mental dos Estados Unidos, publicou no Jornal de Medicina New England o primeiro artigo de pesquisa sobre DDA em adultos que sugeriam esta desordem quando eram crianças, tomando assim público, que este tipo de desordem também ocorre em adultos.

A Autora, Kathleen G. Nadeau é Ph.D, durante anos se dedica aos fatores multidimensionais desta desordem, é autora de outros livros que tratam do mesmo tema. É diretora dos Serviços Psicológicos Chesapeake de Maryland, e membro do Comitê Nacional de Questões dos Adultos da CH.A.D.D e é membro do Conselho de Diretores do Centro Nacional de Leis e Dificuldades de Aprendizagem.

Sob a forma de um guia, o livro foi escrito para esclarecer respostas de questões comuns do dia-a-dia da vida de um adulto com esta síndrome.

Está subdividido em Prefácio, onde Mary McDonald Richard, da Universidade de Iowa apresenta a Autora e o seu percurso profissional, a importância deste trabalho para o leitor construir um melhor estilo de vida e conviver adequadamente com este tipo de problema.

Segue-se ao Prefácio os agradecimentos feitos pela autora à todos os que de alguma forma colaboraram para a realização deste projeto (membros do Montgmery County CH. D.D.A, adultos DDA).

Na Introdução a autora faz uma explanação dos objetivos do livro que é fornecer ao leitor estratégias práticas e concretas para lidar com a desordem, salienta sobre o formato do livro que surgiu de sua prática clínica com adultos e sobre as questões levantadas pelos mesmos, informações básicas, processo diagnóstico.

A intenção da Autora é que os três primeiros capítulos do livro fornecem ao leitorrespostas informativas, breves e atualizadas sobre: O que é Desordem por déficit de Atenção? Como é diagnosticada? Como é tratada?

A porção "solução" deste livro, ou seja, ferramentas, tipos e estratégias é destinada a responder amplamente situações da vida que são afetadas pela desordem e fornecer estratégias práticas e acomodações.

O livro contém 12 capítulos e no final há uma lista de recursos, tais como livros, escolas, artigos, vídeos, tapes, organizações, jornais, serviços on-line seguidos de endereços para contato. As Referências Bibliográficas vêm a seguir e por fim o Índice que é organizado por assunto em ordem alfabética. 
Sua leitura é agradável e informativa, tornando assim o texto claro, direto, breve e prático.

A Autora utiliza o termo DDA, do começo ao fim do livro, para incluir todos os tipos de desordens de déficit de atenção.

O livro inicia com um capítulo "Compreendendo o adulto DDA", que descreve a história desta desordem reconhecida recentemente, sua definição segundo o DSM-IV (Manual Diagnóstico Estatístico das Desordens Mentais) publicado pela Associação Americana de Psiquiatria em 1994, que refere DDA coma Desordem por Déficit de Atenção/Hiperatividade com três subtipos:

. Tipo Predominantemente Hiperativo - Impulsivo

. Tipo Predominantemente Desatento

. Tipo Combinado (reúne critérios de ambos)

Ela discute os sintomas como distraibilidade, desorganização, esquecimentos, tendência para perder objetos pessoais, para falar muito, dificuldade para terminar tarefas, dificuldade para ouvir, tendência para interromper os outros, dificuldade para esperar a sua vez, baixa concentração, pouca habilidade para concentrar-se, entre outros.

Provavelmente as causas desta desordem tenham uma base genética, a autora discute os problemas e porquês do diagnóstico tardio, da dificuldade de diagnóstico, da relação desta com outras desordens como depressão, alcoolismo etc. Este primeiro capítulo é repleto e rico de informações tão necessárias à compreensão desta desordem.

A Autora denomina o segundo capitulo como: "Diagnosticando o adulto DDA" fornece ao leitor todo o processo diagnóstico, desde o profissional mais qualificado para isso, uma lista de testes psicológicos utilizados (Wais, Matchinhg, Wiscosin, etc), testes médicos (eletroencefalograma, tomografia, PET SCAN) e todas as condições que podem coexistir como depressão, mania, dificuldade de aprendizagem entre outras.

No Capítulo 3 a autora enfatiza o "Tratamento para DDA: Medicação e Psicoterapia", afirmando que não é uma desordem psicológica, é uma desordem neurobiológica freqüentemente acompanhada par questões psicológicas.

Ela acredita que o tratamento deve ser feito por uma equipe multiprofissional (psicólogo, médico, educador etc). Denomina os principais medicamentos que são utilizados para o tratamento (estimulantes como a Ritalina, Dexedrine entre outros). Salienta a importância de desenvolver um programa de tratamento.

Um dos mais longos é o quarto capítulo: "Aprender habilidades para a administração da vida", onde a Autora se detém em como desenvolver novos hábitos de como planejar o dia, anotando tudo o que a pessoa deverá fazer, para não esquecer. A Autora dá dicas de como planejar o tempo e como evitar as armadilhas (como chegar cinco minutos mais cedo nos compromissos, começar e terminar tarefas etc), apresenta uma lista que pode diminuir o impacto negativo da DDA no dia-a-dia como sono, dieta, stress, exercícios, administração do dinheiro, hiperatividade, impulsividade, memória e afirma que o importante é ser organizado.

Outro capítulo longo é o quinto, "Construir um casamento forte", onde é discutido todo o impacto que a desordem promove quando não é reconhecida e compreendida pelos parceiros, num casamento. Levanta aqui questões chaves tais como: hipersensibilidade, instabilidade emocional, necessidade de ordem, baixa tolerância à frustração; enfim a necessidade do parceiro em saber lidar com as dificuldades. Houve a preocupação de responder neste capítulo todos as aspectos 
vivenciados num casamento desde a explicação da DDA para o companheiro(a), quando a desordem é utilizada como desculpas, as necessidades do parceiro(a) que não é portador da desordem, da construção de um relacionamento complementar e não co-dependente, a intimidade emocional dando dicas, assim também como intimidade sexual onde expõe algumas técnicas que podem auxiliar como: comunicação, relaxamento etc. Este capítulo é destinado ao parceiro portador deste tipo de problema e àquele que não apresenta a desordem, com sugestões para ambos e culmina com a conclusão de que o relacionamento é um desafio, que deve ser focado mais o lado positivo do que o negativo e que deve ser vivenciado pelos dois juntos.

A Autora cita, no Capítulo 6, Ned Hallowell uma notada psiquiatra, especialista em D D A que afirma que uma família que possui um membro portador desta desordem deve aceitar as questões pertinentes à estas, como um fato da vida que têm um impacto positivo e negativo em toda a família, e a partir desta afirmação a autora trata do desafio da mulher em lidar com seu papel (trabalho, dona-de-casa) e organizar o tempo devido ao stress e a irritabilidade provocadas pela desordem, dá dicas de como estabelecer rotinas em casa (refeições, lições, conversas com os filhos), enfim de como conviver em família com a desordem. Este capítulo a autora chamou de "Vida Familiar: Stress e Estratégias".

O capítulo onde a Autora focalizou problemas interpessoais deste tipo de adultos, é onde o leitor poderá reconhecer e desenvolver alguma das técnicas sugeridas para evitar distraibilidade, monólogos, interrupções, pouca habilidade para ouvir, sensibilidade à crítica. Cita alguns exemplos tais como: gravar, ouvir e repetir as próprias palavras, pois isso ajuda a pessoa a aprender a ouvir; atividades físicas aumentam a habilidade em ficar em harmonia, denominou como "Melhorar as habilidades sociais".

O próximo capítulo focaliza problemas profissionais enfrentados pelos adultos, meios de evitar problemas que podem ser gerados, tais como: distraibilidade, administração do tempo, conflitos interpessoais, memória, baixa tolerância à frustração, desorganização, pois para muitos adultos DDA, o sucesso no trabalho têm sido um ideal distante, resultando em sentimentos crônicos de insatisfação. Cita técnicas de êxito no trabalho; como um colega de trabalho pode conviver melhorar com este tipo de pessoa, fornece também informes sobre proteções legais para estes adultos, pelo Americans with Act Disabilities.

A Autora, enfatiza a utilização que as escolas estão fazendo de recursos pedagógicos para complementar e facilitar a vida acadêmica destes estudantes (livros novos, programas de apoio, leis, assistência especializada). Se o leitor não completou seus estudos, certamente nesse capítulo ele encontrará a certeza de que nunca foi tão fácil obter êxito na escola mesmo portando esta desordem, temos que recordar que esse livro se reporta aos Estados Unidos e não diz respeito à realidade do Brasil.

Mulheres e Desordem por Déficit de Atenção é assunto do décimo capítulo, a autora diferencia as questões da desordem entre mulheres e homens, dedica esse capitulo às mulheres, porque a maioria das pesquisas têm se dedicado e focalizado somente as questões da desordem nos homens. Esclarece as dificuldades mais comuns enfrentadas pela mulher (papel social, expectativas, carreira, casamento, divórcio ), há uma explicação da influência hormonal durante o período menstrual e suas conseqüências (oscilação de humor, de temperamento etc ).É um capitulo complementado por depoimentos de mulheres DDA, enriquecido assim com exemplos, salientando a dificuldade da mulher que ainda sofre forte pressão social para fornecer cuidados para os outros 
(filhos, marido, casa) enquanto os homens parecem já haver descoberto um sistema de apoio.

Há uma lista de como a mulher pode fazer para melhorar sua vida: informar o marido a respeito do seu problema e como isso a afeta; simplificar a sua vida; construir um grupo de apoio para ela (amigos, colegas, família); passar um tempo fora (férias, finais de semana); focalizar nas coisas que ela ame, entre outras.

A avaliação e criação de recursos, neste capítulo a autora se deteve em dar dicas ao leitor em como criar recursos na comunidade da qual ele faz parte e avaliar aqueles recursos já existentes.

Também esclarece alguns mitos, como por exemplo: - "Eu não posso ter DDA e chegar a ser um PhD." Neste momento cita o caso do Dr. Ned Hallowell que é um notável psiquiatra, um perito desta desordem e também portador da mesma; um outro mito citado é: "O melhor meio para o diagnóstico é dar uma medicação estimulante e medir uma resposta disto" entre outros. O capítulo culmina com um auxílio ao leitor de como montar um grupo de adultos (grupo de apoio, informações, orientação, contatar com demais grupos já existentes). Ela reforça: "Não fique parado, faça alguma coisa!".

No último capítulo entitulado "Estórias de sucesso" são relatadas histórias de pessoas com idade entre 19 e 74 anos, que aprenderam a conviver com a desordem aprendendo a solucionar problemas. Cita o caso de uma mulher que recorda suas frustrações escolares e de relacionamentos familiares, desde pequena e após ter descoberto que apresentava a desordem, procurou tratamento adequado como médico e psicoterapêuta, conseguiu obter êxito na faculdade e conviver melhor com sua própria família.

Uma breve conclusão encerra o capítulo incentivando e encorajando o leitor a buscar informações, tratamentos adequados para a desordem, aprendendo a buscar soluções, principalmente mostrando ao leitor como descobrir seu lado mais positivo e focar aquilo que ele pode fazer e não o que ele não pode.

Segue-se uma ampla lista de recursos, assim também como referências atualizadas e o índice finaliza o livro.

Com 209 páginas, o livro vêm sob a forma de perguntas e respostas fornecendo fácil acesso à informações independentes. O livro é de prático manuseio. Sua linguagem é clara e informativa, apesar dos termos científicos utilizados principalmente nos capítulos iniciais.

A leitura é agradável tomando o texto claro, direto, breve e prático.

O objetivo da autora parece ser cumprido, ela cerca todos as segmentos da vida de um adulto DDA e fornece estratégias para soluções dos principais problemas enfrentados por estes adultos (família, casamento, trabalho, estudo, profissão).

Muito embora apesar da vasta, detalhada e riquíssima informação contida, o livro de forma alguma consegue substituir o tratamento psicoterápico e médico tão necessários à estas pessoas. Poderá sim, ser um auxiliar paralelo durante o tratamento.

Coma afirma a Autora, o livro é um guia prático para o dia-a-dia.

Este livro destina-se aos adultos portadores dos problemas da Desordem par Déficit de Atenção, assim como a parentes, pais e a todos aqueles que queiram aprender mais sobre esta desordem recém descoberta e que afeta a vida do adulto de maneira global.

Edyleine Bellini Peroni Benezik 